\title{
Editorial
}

\section{Man and Environment in Forest and Steppe Zone of Eurasia: Past, Present and Future}

This issue of The Open Geography Journal dedicated to the topics of the International Conference "Man and environment in boreal forest zone: past, present and future" that held July 24-30, 2008 in the Central Forest State Natural Biosphere Reserve (Tver' region, Valdai Hills, European Russia) and organized by the Environment Evolution Commission of International Geographical Union and the Russian Academy of Science. The main goals of the issue are to discuss the different problems of environmental evolution of forest and steppe zones in Europe in the Pleistocene and Holocene, to quantify and analyze the modern and proposed future climatic trends for the area, and to estimate human impact on forest and steppe ecosystems under present and future climatic conditions.

An evolutionary analysis of terrestrial environments is necessary for understanding the contemporary state of this system, estimating its stability and variability under influence of closely interrelated natural environmental trends and anthropogenic impacts. Thus, a natural trend towards cooling, identified from paleogeographic data, is superimposed upon the process of the man-induces warming. Such a combination of governing factors influencing the landscape-climatic system in opposite directions brings about its diminishing stability.

The special issue includes the papers devoted to a wide range of problems in a frame of IGU Environment Evolution Commission's activity, such as human-environment interaction in the past, landscape evolution in the Pleistocene and Holocene, modern and future climatic changes, anthropogenic impact on forest and steppe ecosystems, modelling approaches of land surface and atmosphere interaction. These activities are carried out in close cooperation with the Northern Eurasia Earth Science Partnership Initiative (NEESPI) that is aimed at developing an enhanced understanding of the interactions between the ecosystem, atmosphere, and human dynamics in northern Eurasia (http://neespi.org/).

\section{THE MAIN TOPIC OF THE ISSUE:}

1. Landscape and climate dynamics in the forest and steppe zones of Europe in the Pleistocene and Holocene.

2. Human - environment interaction and land use dynamic in the Holocene.

3. Observed modern and proposed future climatic trend.

4. Anthropogenic impacts on forest ecosystems.

5. Forest ecosystems under climatic changes.

The above-mentioned interrelated problems may be considered as the basis of the scientific collaboration of international community for investigation of environment evolution and prognosis.

Elena Novenko

(Guest Editor)

Environment Evolution Commission of IGU

Institute of Geography of the Russian Academy of Science

Russia

E-mail: lenanov@mail.ru

$\begin{array}{r}\text { Alexander Olchev } \\ (\text { Co-Guest Editor })\end{array}$
A.N. Severtsov' Institute of Ecology and Evolution of the Russian Academy of Science
Russia
E-mail: aoltche@gmail.com

(C) Novenko and Olchev.; Licensee Bentham Open.

This is an open access article licensed under the terms of the Creative Commons Attribution Non-Commercial License (http://creativecommons.org/licenses/by$\mathrm{nc} / 3.0 /$ ) which permits unrestricted, non-commercial use, distribution and reproduction in any medium, provided the work is properly cited. 